\title{
Metabolic and Anti-Inflammatory Effects of Antidepressants in Patients Diagnosed with Major Depressive Disorder: A Prospective Cohort Study
}

Osamah Hussein ( Osama.h@ziv.health.gov.il)

Ziv Medical Center

Lidia Izakson

Bar-Ilan University

Jamal Zidan

Bar-llan University

\section{Research Article}

Keywords: major depression disorder, inflammation, metabolic disorder, oxidative stress, endothelial injury

Posted Date: December 1st, 2021

DOI: https://doi.org/10.21203/rs.3.rs-1027124/v1

License: (c) (i) This work is licensed under a Creative Commons Attribution 4.0 International License. Read Full License 


\section{Abstract \\ Introduction:}

There is growing evidence showing a correlation between major depression disorder (MDD), metabolic syndrome and inflammation. To examine the influence of antidepressant medications on the metabolic, inflammatory profiles, oxidative stress and endothelial derangement of patients suffering from MDD.

\section{Results}

Depressive patients displayed significantly higher serum triglycerides than control group, which increased significantly during eight weeks of antidepressive treatment. In the patients' group, serum levels of ALT and AST increased significantly during treatment. Serum peroxide level was significantly higher in patients before and during treatment vs. controls and decreased significantly in the patients' group during treatment. Macrophage chemoattractant protein-1 and hs-CRP serum levels were higher in patients before treatment as compared with controls. The percentage of gated IgM $\mathrm{CD}_{19}{ }^{+}$and $\mathrm{CD} 14^{+}$cells in depressive patients before treatment was significantly higher than in the control group. The percentage of $\mathrm{T}$ regulatory cells increased significantly during antidepressive treatment.

\section{Discussion}

MDD patients had increased oxidative stress, inflammatory responses, metabolic derangements and endothelial injury. Antidepressant medications increased the percentage of $T$ regulatory cells.

\section{Methods}

Twenty-nine patients aged 22-58 who were diagnosed with MDD but not medicated, were selected for the study. During the 8-week duration of the research, patients received anti-depressant medication.

\section{Introduction}

Major depressive disorder (MDD) is characterized mainly by loss of energy and interest, feelings of guilt, difficulty in concentrating, decreased or increased appetite, thoughts of death and suicide and a depressive mood.

MDD, diagnosed according to the DSM-IV-TR criteria for major depressive episode, has the highest lifetime prevalence of any psychiatric disorder (about 17\%), and has a two-fold higher prevalence in women than in men. There is growing evidence showing a correlation between depression, metabolic syndrome (MetS), diabetes, cardiovascular disease, serum lipid profile (Lehto et al. 2010b; van Reedt Dortland et al. 2010), body weight and the immune system, as well as the effects of some antidepressant medications on these various conditions and profiles (Paslakis et al. 2011). Depressed patients often have changes in their metabolic profiles and weight because of lifestyle changes due to the depressive illness, but also because of the effects of the medications. A recent study from the Netherlands suggested that the unfavorable lipid /lipoprotein pattern among depressed subjects was largely secondary to lifestyle-related factors (van Reedt Dortland, 2010). However, melancholic features have been independently associated with lower highdensity lipoprotein cholesterol (HDL-C) and atypical depression has been independently associated with higher total and low-density lipoprotein (LDL) cholesterol (van Reedt Dortland et al. 2010). Other studies showed a beneficial effect of antidepressants on lipid regulation, glycemic control and insulin sensitivity (Kopf et al. 2004; Lustman et al. 2000). A 
more recent study showed the beneficial effects of the antidepressant drug reboxetine on serum LDL-C level, body mass index (BMI) and mean systolic blood pressure (BP) in patients with metabolic syndrome (MetS) (Paslakis et al. 2011).

MetS includes a cluster of risk factors for atherosclerotic cardiovascular disease (ASCVD) with assumed insulin resistance basis (Grundy 2007; Grundy et al. 2005). It consists of increased waist circumference, atherogenic dyslipidemia (ie, elevated triglycerides, small dense LDL and low serum HDL-C), elevation of blood pressure (BP) and glucose, and prothrombotic and proinflammatory states. Many patients with MetS have insulin resistance which predisposes them to either a prediabetes state (impaired fasting glucose: fasting glucose $\geq 100 \mathrm{mg} / \mathrm{dL}$ and $<126 \mathrm{mg} / \mathrm{dL}$ or impaired oral glucose tolerance test: 2 hour glucose level $\geq 140 \mathrm{mg} / \mathrm{dL}$ and $<200 \mathrm{mg} / \mathrm{dL}$ ) or type 2 diabetes mellitus. Obesity and physical inactivity are the first hit with genetic determined metabolic susceptibility as the second hit (Grundy 2007).

MetS is often associated with other medical conditions, notably, non-alcoholic fatty liver disease, cholesterol gallstones, obstructive sleep apnea, gout, depression, musculoskeletal disease, polycystic ovarian syndrome and specific cancers. The risk for ASCVD is approximately doubled in MetS patients as compared to those without the syndrome. For example, a recent meta-analysis including 43 cohorts (172,573 individuals) reported that metabolic syndrome conveyed a relative risk (RR) for CVD events and death of 1.78 (Gami et al. 2007). In women, the risk was higher (RR 2.63). In addition, risk was still associated with the syndrome after adjusting for traditional CVD risk factors (RR 1.54); this finding indicates that risk accompanying the syndrome cannot be explained entirely by the latter. Other reports also support the conclusion that MetS entails increased risk for CVD (Despres and Lemieux 2006).

Stress, a major risk factor of MDD, is associated with the activation of the hypothalamic-pituitary-adrenal axis, leading to the release of catecholamines, which in turn, activate the NLRP3 inflammasome (Miller and Raison 2016). The inflammasome drives the secretion of IL-1 $\beta$ which increases inflammatory response in MDD patients (Broz and Dixit 2016).

The coexistence of increased indoleamine 2,3-dioxygenase and the anti-inflammatory role of which is in part mediated by $T$ regulatory cells (Treg cells) with an inflammatory state is paradoxical and could suggest a defect in Tregs in MDD mediated by inflammation.

As for the innate immune system, selective serotonin reuptake inhibitors (SSRIs) may reduce levels of IL-6 and TNFa, whereas other types of antidepressants do not appear to reduce cytokine levels or have shown evidence of such in only a few studies (Eyre et al. 2016).

Both the adaptive and innate immunity are affected by MDD (Miller 2010), which in turn affects the cardiovascular system and the inflammatory profile of the patients (Hansson and Libby 2006). Norepinephrine has been shown to affect B- and T-cells (Kin and Sanders 2006). Changes in interferon-y production by T helper 1 cells (Th1) depend on when $\mathrm{CD} 4^{+} \mathrm{T}$-cells are exposed to norepinephrine: before, during, or after T cell receptor (TCR) stimulation. Changes in Th1 cells alter signaling to activate macrophages, natural killer (NK) cells and CD8 ${ }^{+}$T-cells. Moreover, CD95 expression is elevated on $\mathrm{CD}^{+}$cells in depressive patients and could explain elevated apoptosis observed in those cells (Miller 2010). This elevated apoptosis could then add to plaque vulnerability in the atherosclerotic process.

Treg cells, which have a role in controlling inflammation, are hypothesized to be insufficient in inflammatory diseases such as MDD. While there is little data about Tregs in depressive patients, their rates were found to be lower in PTSD patients (Miller 2010). Moreover, Tregs are known to produce IL-10 (George et al. 2012) and TGF- $\beta$ (Robertson et al. 2003), which are antiatherogenic. 
It has been proposed that Tregs are involved as a possible "inverted pyramid" in the inflammatory process, leading to atherosclerosis and acute myocardial infarction (AMI) (Bodi et al. 2008).

Natural killer (NK) cells have long been a subject of investigation in depressive patients, with the overall data indicating that depressed patients have lower NK cell cytotoxic activity and lower NK cell numbers in peripheral blood. Some studies did not find a difference in percentages of NK cells, but did find that lower NK activity changed with treatment. This could possibly be explained by the subset CD56 ${ }^{\text {bright }}$ NK cells (Poli et al. 2009), which have been shown to have lower cytotoxic activity but higher cytokine production than the more common CD $56^{\mathrm{dim}} \mathrm{NK}$ cells.

There is still a gap in knowledge concerning the interrelationships between innate and adaptive immune system and metabolic derangements from one side and between oxidative stress and endothelial dysfunction from other side. Oxidative stress measured by serum peroxides, inflammatory process and endothelial dysfunction measured by ADMA are considered as the early steps of arterial atherosclerosis.

In this study, the aim is to examine the influence of antidepressant medications on the metabolic and inflammatory profiles, oxidative stress and endothelial derangement of patients suffering from MDD, which can promote atherosclerosis.

\section{Results}

Anti-depressive therapy decreased Hamilton Depression Rating significantly by $60 \%$ (Table1). Patients denied using nonsteroidal anti-inflammatory drugs, omega-3 fatty acids, n-acetylcysteine, L-arginine, probiotics, curcumin or saffron during the study. No malignant disease, coronary artery disease, irritable bowel disease, diabetes mellitus or rheumatic disease was diagnosed before or during the study period.

Number of patients that were treated with each drug:

Antidepressive therapy: venlafaxine (13), duloxetine (1), milnacipran (1), escitalopram (6), sertraline (3), paroxetine (4), citalopram (1)

Benzodiazepines: lorazepam (4), clonazepam (2).

\section{Metabolic derangements}

Depressive patients displayed $40.7 \%$ higher serum triglycerides than the control group, a significant difference. During 8 weeks of anti-depressive treatment, the serum triglyceride level in the depressive patients increased significantly by $22 \%$ (Fig. 1). Apo E was lower in the patients by $46.2 \%$ compared to the control group and did not change significantly during treatment (Fig. 1). Body weight (Fig. 1) and sitting diastolic blood pressure (Fig. 2) were significantly higher by $0.7 \%$ and $6.4 \%$, respectively, in the depressive group, as compared to the control, and did not change significantly following treatment. Sitting diastolic pressure was significantly higher by $12 \%$ in the depressive group during treatment as compared with the control group at visit 2 (Fig. 2). The patients' group average body weight was $7.7 \%$ higher compared to the control group, a non-significant result (Fig. 1). Waist circumference was greater by $9 \%$ in the patients during therapy compared with the control group, also a non-significant result (Table 1).

In the patients' group serum levels of ALT and AST increased significantly by $63.3 \%$ and $39 \%$, respectively, during treatment compared with baseline level with ALT/AST ratio>1 (Fig. 2). There was no difference between patients (before and after treatment) and controls in: serum levels of fasting glucose, HOMA-IR, HOMA-beta, uric acid, total cholesterol, HDL-C, calculated LDL-C, apo B, apo A-I, apo A-II, YGT, BMI and sitting systolic blood pressure (Table 1). 


\section{Oxidative stress}

Serum peroxide level was significantly higher by $66.7 \%$ and $160 \%$ in patients before and during treatment, respectively, as compared with the controls (Fig. 3). Serum levels of 8-iso-PGF, basal MDA, MDA after serum peroxidation and its change from basal MDA (delta MDA) and conjugated dienes after serum peroxidation, were not different between controls and patients at baseline, nor were they different between patients at baseline and during treatment (Table 1).

PON arylesterase activity in the control group increased significantly by $33.4 \%$ in the second visit compared with the first visit (baseline) and decreased significantly by $19.1 \%$ in the patients' group during treatment vs. before treatment. PON arylesterase activity was $29.9 \%$ lower in patients during treatment compared with controls during visit 2, a significant value (Fig. 3). SOD activity in the depressive group increased significantly by $29.7 \%$ during treatment as compared with visit 1 before start of treatment (Fig. 3).

\section{Endothelial injury}

Serum ADMA levels were significantly higher by $53.2 \%$ and $41.3 \%$ in patients before and during treatment, respectively, compared with controls (Fig. 4).

\section{Inflammation}

Serum MCP-1 levels were higher by $227 \%$ in patients before treatment as compared with controls; furthermore, they increased significantly during treatment by $13.5 \%$ as compared to before treatment began (Fig. 4). hsCRP serum levels were $418.2 \%$ higher in patients before treatment as compared with controls. This level in patients did not change during treatment and was similar to the level in controls (Fig. 4). There was no difference in VCAM-1 levels between control and patient groups or between patient levels before and during treatment (Table 1). In unmedicated depressive patients at visit 1, there was no correlation between HDRS and MCP-1, hs-CRP or VCAM-1. The difference in HDRS between visit 1 and visit 2 was correlated with the difference in MCP-1 between visit 1 and visit $2(r=0.408, p<0.05)$. The percent of gated IgM CD19+ cells in depressive patients before treatment was significantly higher (by 1.21 fold) than in the control group (Fig. 4). The percent of gated IgG CD19+ cells in depressive patients before treatment was 1.4-fold higher than in the control group ( $p=0.06$ ), a non-significant result (Table 2 ). Antidepressive therapy did not change the percent of either gated IgM CD19 ${ }^{+}$cells or IgG CD19 ${ }^{+}$in depressive patients. The percent of CD14 ${ }^{+}$cells (monocytes) in depressive patients before treatment was significantly higher (by $1.21 \mathrm{fold}$ ) than in the control group (Fig. 5). The T cell/monocyte ratio was lower by $27 \%$ in depressive patients before treatment as compared with the control group and did not change during antidepressive treatment (Fig. 5). The percent of Treg cells increased significantly by $53 \%$ during antidepressive treatment (Fig. 4). The percent of CD19 ${ }^{+}$cells, gated CD56 ${ }^{+}$lymphocytes, NK FS SSC lymphocytes, CD $56^{+}$MFI NK FS SSC cells and CD $16^{+}$MFI NK FS SSC cells showed no differences between the control and patient groups or within the patient group before and during treatment (Table 2).

When taking into account patients who were treated by SSRI (14 patients) or SNRI (12 patients), MCP-1 levels in patients before treatment were significantly higher compared with controls. These levels further increased during treatment with SSRI and did not change during treatment with SNRI. VCAM-1 and hsCRP did not change during treatment with SSRI or SNRI (results not shown).

\section{Discussion}

\section{Metabolic parameters}


In the present study, depressive patients at baseline (before pharmacotherapy) exhibited metabolic derangements including increased fasting serum triglyceride levels and decreased serum apo E as compared with the control group. No associations were found between apoe genotypes and measures either of past-year or life time MDD (Surtees et al. 2009). In our study, a decreased fasting apo E level and increased triglyceride level in MDD patients may represent a phenotype of large very-low-density lipoprotein (VLDL), which is part of the metabolic dyslipidemia. In accordance with a previous study (Kotan et al. 2011), our patients' serum levels of apo B did not differ before vs. during antidepressive treatment, nor as compared with the control group. This also confirms that increased levels of triglycerides in depressive patients is not due to increased number of VLDL particles. In previous studies of MDD patients, elevated serum apo B levels were found when compared with the control group (Sadeghi et al. 2011; Sarandol et al. 2006), but with no change in the patient group during antidepressive therapy (Sarandol et al. 2006).

In our patients, during anti-depressive treatment, serum triglycerides and ALT increased with ALT/AST>1, which is a surrogate marker of non-alcoholic fatty liver. This can reflect a state of insulin resistance. HOMA-IR and waist circumference increased, though without statistical significance, perhaps due to the power of the study or to the short study duration.

\section{Oxidative stress}

Serum peroxide levels were higher in MDD patients as compared to the control group and further increased during antidepressive treatment. This is comparable to previous studies in which the MDA level was higher in depressive patients (Galecki et al. 2009; Kotan et al. 2011; Sarandol et al. 2007; Szuster-Ciesielska et al. 2008). There are different parameters for increased oxidative stress. In the initiation phase, there is an increase in the formation of conjugated dienes (CD), followed by peroxide formation in the propagation phase with malondialdehyde as secondary products during lipid peroxidation. $C D$ is a dynamic and time-consuming test but it is not a relevant clinical test. Peroxide production is a simple laboratory test and is relevant for clinical use. The higher levels of peroxides in MDD patients in the present study decreased the PON arylesterase activity during treatment as anticipated, due to the inactivation of the enzyme by reactive oxygen species (Aviram et al. 1999). The same reduction in PON arylesterase activity during 6 weeks of antidepressive therapy was also reported in another study (Sarandol et al. 2006). In contrast, yet another study reported serum PON arylesterase activity to be lower in MDD patients as compared to the control group, but increased significantly after 24 weeks of antidepressant treatment to reach the normal range (Kotan et al. 2011). The differences in the results of these studies in PON arylesterase activity may be due to different content of dietary antioxidants, cigarette smoking, the specific antidepressive treatments utilized or the duration of treatment.

In the present study, the serum activity of SOD in MDD patients increased during treatment as a response to the increased oxidative stress, since SOD is a first line of defense against oxidative stress development. The same results were observed in previous studies (Kotan et al. 2011; Sarandol et al. 2007; Szuster-Ciesielska et al. 2008). In contrast, other studies showed contradictory results with a decrease in SOD activity in patients when compared to controls (Herken et al. 2007; Stefanescu and Ciobica 2012). Moreover, RBC-SOD activity in MDD patients decreased during treatment with antidepressant medication (Kotan et al. 2011). Galecki et al (2009) indicated that fluoxetine did not reduce the MDA level after 3 months of treatment. Sarandol et al (2007) found no change in serum MDA levels in depressive patients between the pretreatment and the 6 weeks of antidepressive treatment (venlafaxine, reboxetine or sertraline). On the contrary, escitalopram and venlafaxine increased serum MDA level after treatment and decreased serum SOD activity (Stefanescu and Ciobica 2012). It does not seem that the differences is due to SNRI or SSRI treatment.

In summary, in the present study, depressive patients had increased oxidative stress, which resulted in reduced PON arylesterase activity and increased serum SOD activity. This increased oxidative stress was not contained during 
treatment with antidepressants.

\section{Endothelial injury}

ADMA levels, as a marker of endothelial injury, were higher in MDD patients before and during treatment. The same results were reported in a previous study by Selley (2004). In the present study, serum VCAM-1 levels did not differ between the control and patient group before and after treatment. The same results had been reported in a study by Dawood et al (2016), which also demonstrated that SSRI therapy did not influence endothelial function or markers of vascular or platelet reactivity.

\section{Inflammation}

Serum MCP-1 and hsCRP levels before antidepressive treatment were higher in MDD patients compared with the control group. In a meta-analysis on 31 cross-sectional studies on IL- 6 and 20 studies on CRP there were positive associations between increased levels of IL-6 and CRP and major depression (Haapakoski et al. 2015). hsCRP was chosen for this study as it is a more sensitive indicator of inflammation, as compared to CRP. In a previous study, average MCP- 1 level was shown to be higher in MDD patients than in controls (Piletz et al. 2009; Sutcigil et al. 2007), in accordance with the present study. Another previous study, however (Lehto et al. 2010a), showed this level to be lower. Increased MCP-1 is an indication of mononuclear cell activation, as part of the active innate immune system. In contrast, no confirmed relation was found between MDD and TNF-a (in 31 studies), nor consistent evidence (in 14 studies) to a link between IL-1 $\beta$ and depression (Haapakoski et al. 2015). In the present study, serum MCP-1levels increased during antidepressive treatment. This is in contrast to a study by Piletz et al(2009), in which treatment by venlafaxine did not alter the MCP-1 level. It was then hypothesized that venlafaxine might fail to exert immune down-regulatory effects, as it is not a pure SSRI. In that study, MCP-1 level was lowered in the serotonergic dose range of venlafaxine. In contrast, in the present study, MCP-1 levels increased significantly or did not change during treatment with SSRI or SNRI, respectively. Differences may also relate to different genetic backgrounds. In dizygotic MDD-discordant twin pairs, twins with MDD had higher myeloperoxidase, interleukin 6 and CRP than their siblings without MDD after adjusting for other factors. In contrast, no significant association was found in monozygotic twins. These results are consistent with the hypothesis that genes promoting inflammation are involved in the pathogenesis of MDD (Vaccarino et al. 2008).

In Toben and Baune's systematic review (2015), blood lymphocyte count was found to be unchanged in MDD patients in most of the 23 studies in which it was recorded. As for the subsets of lymphocytes, MDD is associated with a decreased number of T cells and in vitro down-regulated proliferative response. Darko et al (1989) found no change in T cell proliferation between MDD patients and controls. In the present study, CD3CD45 T cells were lower in MDD patients, both before and during antidepressant treatment as compared with controls.

In our study, the percent of $\mathrm{CD}_{16}{ }^{+} \mathrm{NK}$ cells and $\mathrm{CD} 56^{+} \mathrm{MFI}$ NK cells were not different in patients either before or during treatment vs. controls. Other studies reported that NK cells were similar (Farid Hosseini et al. 2007) or lower (Ivanova et al. 2007) than in the control group. NK cell percentages further increased following treatment by venlafaxine or

fluoxetine for six weeks in responding patients (Basterzi et al. 2010), while CD16 ${ }^{+}$cells did not change in one study (Ying et al. 2002) and decreased in other studies (Li et al. 2010; Sommershof et al. 2009). The explanation for these contradictory results may be due to differences in dietary habits, gender and/or smoking status that may alter immune and cytokine functioning.

In the present study, the Treg cells percent in patients with MDD did not differ from the control group. Even in the presence of normal Treg cell percentages, increased inflammatory response in MDD patients could be due to a decreased function of Tregs, to an increased number or function of effector T cells or to the milieu of the immune response such as increased oxidative stress or endothelial dysfunction, which would affect Treg activity. Treg cell percentages in patients with MDD increased during antidepressive treatment. This was in accordance with a study which 
demonstrated an increase in $\mathrm{CD} 4^{+} \mathrm{CD} 25^{+}$and $\mathrm{CD} 4^{+} \mathrm{CD} 25^{\mathrm{hi}}$ (hi denote high expression of CD25) T regulatory cells in treated depressive patients while the lymphocyte fraction remained constant (Himmerich et al. 2010). That study demonstrated that the more severely depressed the patients were at baseline, the more their $C D 4^{+} C D 25^{\text {hi }}$ proportions increased. In contrast, another study of newly diagnosed MDD patients showed increased Th1/Th2 ratios and a decreased $\mathrm{CD} 4^{+} \mathrm{CD} 25^{+}$Treg cell population in the peripheral blood lymphocytes (Li et al. 2010). On the contrary, it was demonstrated that the more severely depressed the patients were at baseline, the more their $\operatorname{CD} 4^{+} \mathrm{CD} 25^{\mathrm{hi}}$ proportions increased (Himmerich et al. 2010). That study also showed that Foxp3 mRNA levels decreased in the CD $4^{+} \mathrm{CD} 25^{+} \mathrm{Treg}$ cells and in the whole peripheral lymphocytes of the MDD patients, while the 5-HT1aR expression decreased only in the CD $4^{+}$CD $25^{+}$Treg cells (Li et al. 2010). In the present study, we confirmed that antidepressive therapy increased the percentage of Treg cells. Foxp3 is an important measure, as Foxp3 expression in mature Treg cells is needed to maintain the transcriptional and functional program established during Treg cell development (Williams and Rudensky 2007). Treg cells may have a role in reducing an inflammatory response (Miller 2010). Treg cells steer monocyte differentiation towards alternatively activated macrophages, which have strong anti-inflammatory potential (Tiemessen et al. 2007). $\mathrm{CD} 4^{+} \mathrm{CD} 25^{+}$cells are potent suppressors of the adaptive and the innate immune system, a fact that indicates the importance of these cells in MDD. On the other hand, downregulation of IL-1b during antidepressant treatment may upregulate Treg cells because IL-1b can induce the conversion of Treg cells into proinflammatory T helper (TH)-17 cells (Deknuydt et al. 2009). In MDD patients, personal habits and social factors that in $\square$ uence patients' diet, hygiene, accessibility to health care system and exposure to infectious microbes, can affect immune homeostasis, microbiome and systemic inflammatory response, modulating the immune system milieu. Therefore, different study MDD populations can present different results. In the present study, patients with uncontrolled metabolic diseases, tobacco smoking or alcoholism were excluded in an effort to decrease the effect of environmental factors. In a systematic review, it seems that cognitive behavior therapy has anti-inflammatory effects (Lopresti 2017). This therapy was not implemented during the period of the present study.

In a review of five studies in MDD patients by Toben and Baune (2015), three studies showed an increase in the percent of $\mathrm{CD} 4^{+} \mathrm{T}$ cells, while two studies reported an increased $\mathrm{CD} 4^{+} / \mathrm{CD} 8^{+}$ratio. These studies indicate that $\mathrm{CD} 4^{+} \mathrm{T}$ cells in MDD patients are involved in perpetuating the neuroinflammation. Another study reported accelerated apoptosis of CD $4^{+}$ T cells (Szuster-Ciesielska et al. 2008) which could suppress the proliferation and/or cytokine production of CD $4^{+} \mathrm{T}$ cells (Annacker et al. 2001). In MDD patients, the proportion of CD4 ${ }^{+}$was lower than in the control group (Ivanova et al. 2007), or with no significant difference (Farid Hosseini et al. 2007). Yet another study found the percentage of CD $4^{+}$cells significantly decreased after treatment by venlafaxine, whereas the levels of CD8 ${ }^{+}$cells remained unchanged (Fazzino et al. 2009). IN 1998, Karlsson et al. had hypothesized that escitalopram can induce apoptosis in proliferating lymphocytes. In the present study, blood $\mathrm{CD}^{+} \mathrm{T}$ cells were lower in MDD patients than in controls, with no change in MDD patients during antidepressive treatment. Other studies have found varied and contrasting results where, in MDD patients compared with controls, the percent of $C D^{8}$ cells either remained unchanged (Levy et al. 1991; Muller et al. 1993; Ravindran et al. 1998), increased (Pavon et al. 2006) or decreased (Marazziti et al. 1992).

In conclusion, our study clearly showed that MDD patients had: increased oxidative stress measured by serum peroxides; increased innate immune response measured by serum MCP-1, hsCRP and $C D^{14}$ cells and adaptive immune response measured by IgM CD ${ }^{19+}$; metabolic derangements; and endothelial injury measured by serum ADMA.

For each one of these pathological processes, not all parameters were in the same direction, pointing to the interrelated relations between different systems and the environment.

Antidepressant medications increased the percentage of Treg cells possibly due to reduction in IL-1 $\beta$, which may have a role in suppressing inflammatory response by reducing $C D^{3} C D^{45}$ cells and reducing endothelial injury. 


\section{Methods}

This prospective cohort study was registered as NCT01418638 at ClinicalTrial.gov. Protocol registration receipt on 16/08/2011. All methods were performed according to our local guidelines and regulations.

\section{Participants.}

Twenty-nine white patients, mean age $42.8 \pm 12.0$ years, of them 14 females, who were diagnosed with MDD according to the DSM-IV criteria were selected for the study. A control group included 10 white, healthy non-smoking participants, with no mental health diseases, mean age $36.5 \pm 9.5$ years, of them 6 females. No significant difference in the mean age of the two groups ( $p=0.09)$. The Institutional Ethics Committee of Ziv Medical Center approved the study (0001-11-ZIV). Participants signed written informed consent forms prior to enrollment to the study by an accredited, independent psychiatrist. Inclusion criteria were MDD-diagnosed, non-smoking naïve patients with a Hamilton Depression Rating Scale (HDRS) Score of at least 18 points. Patients included in the study had not been treated with medications or such that had shown resistance to treatment, nor had they been treated by cognitive behavior therapy, and were therefore assigned for drug replacement. Patients on stable therapy for hypertension, diabetes mellitus, hypothyroidism, dyslipidemia and/or weight lowering medications were included.

Exclusion criteria were patients who had received antipsychotic treatment and /or mood stabilizers. Patients with uncontrolled diabetes mellitus, uncontrolled thyroid functioning, uncontrolled hypertension or uncontrolled malignancy, as well as smokers and those who regularly consume alcohol, were excluded. Patients and controls have no acute febrile disease or known chronic inflammatory disease.

\section{Research Design.}

Duration of research was 8 weeks. Base line was considered the time of recruitment (before start of treatment). During the 8-week duration of the research, patients received anti-depressant medication. Serotonin-norepinephrine (noradrenaline) reuptake inhibitors (SNRIs) were given to 12 patients (combined in one patient with a tetracyclic antidepressant and in another with a tricyclic antidepressant) and selective serotonin reuptake inhibitors (SSRIs) to 15 patients (combined with tetracyclic antidepressants in five patients); one patient switched from SSRI to SNRI and other patient vice versa.

A follow-up HDRS was performed at weeks four and eight. A psychiatrist from the Department of Psychiatry who was blinded to the identity of the study participants performed the psychiatric evaluation. The decision on treatment choices was done at the discretion of the blinded psychiatrist.

\section{Measures.}

The following metabolic parameters were measured at base line and at the end of 8 weeks:

Weight, height, waist circumference, body mass index (BMI: (Weight in $\mathrm{Kg} /\left(\right.$ Height in meters) ${ }^{2}$ ), sitting systolic and diastolic blood pressures (after 3 minutes of sitting) and brachial pulse rate.

Blood tests were drawn after 8 hours overnight fast.

Serum lipid profile was performed in our medical center's chemistry lab: low-density lipoprotein cholesterol, high-density lipoprotein cholesterol, triglycerides, total cholesterol, apolipoproteins serum levels (apo Al, apo B, apo E, apo All) and serum activity of aspartate transaminase (AST) and alanine transaminase (ALT), gamma-glutamyl transferase (GGT), uric acid and alkaline phosphatase. Fasting serum glucose and insulin blood levels were measured to evaluate insulinrelease and resistance, according to the following formulas: 
Insulin resistance: HOMA IR=Fasting glucose $(\mathrm{mg} / \mathrm{dL})$ x Fasting insulin $(\mathrm{mmol} / \mathrm{L}) / 405$

Insulin release: HOMA- $\beta=(360 \times$ fasting insulin $(\mathrm{mmol} / \mathrm{L})) /($ glucose $(\mathrm{mg} / \mathrm{dL})-63)$

Serum oxidative stress according to the 8-isoprostane (8-iso-PGF2a) as an index of total oxidative stress (Assay Designs, Ann Arbor, Michigan) was measured. Malonyldialdehyde (MDA) content in serum was analyzed by the thiobarbituric acid reactive substances assay, which measures malondialdehyde equivalent (Aviram 1983). Conjugated dienes were measured at 234nm (Esterbauer et al. 1989; Lowry et al. 1951). Serum peroxides were measured according to a previously described method (el-Saadani et al. 1989).

Serum paraoxonase (PON) activity was determined by an adaptation of the spectrophotometric method of Furlong et al (Furlong et al. 1989). Aliquots $(10 \mu \mathrm{l})$ of diluted (1:5) serum were placed in microliter plate wells in triplicate; the reaction was then initiated by adding $190 \mu \mathrm{l}$ of the substrate $(1.2 \mathrm{mmol} / \mathrm{L}$ paraoxon in $0.26 \mathrm{mmol} / \mathrm{LTris}-\mathrm{HCL}, \mathrm{pH} 8.5,25 \mathrm{mmol} / \mathrm{L}$ $\mathrm{CaCl} 2$ and $0.5 \mathrm{~mol} / \mathrm{L} \mathrm{Nacl})$. After mixing, the plate was read immediately at $450 \mathrm{~nm}$ to establish zero time values.

Readings were repeated at 2-min intervals for $10 \mathrm{~min}$. Non-enzymatic hydrolysis of paraoxon was subtracted from the total rate of hydrolysis. The enzyme activity was calculated from the linear portion of the plot using the molar extinction for $p$-nitrophenol $(17,100 \mathrm{~mol} / \mathrm{L})$. One unit of paraoxonal 1 activity equals $1 \mu \mathrm{mol} / \mathrm{L}$.min of released $\mathrm{p}$-nitrophenol.

PON arylesterase activity was measured by using phenylacetate as substrate. Non-enzymatic hydrolysis of phenylacetate was not observed. The reaction took place in Tris buffer $(50 \mathrm{mM}$ Tris- $\mathrm{HCl}, \mathrm{pH} 8,1 \mathrm{mM} \mathrm{CaCl} 2)$ and was initiated by adding the substrate. Absorbance $(\lambda=270 \mathrm{~nm})$ was measured at zero time and after 2 min. The enzymatic activity was expressed as micromoles of hydrolyzed phenylacetate. $\mathrm{min}^{-1} \cdot \mathrm{ml}^{-1}$ (U/ml) (Gan et al. 1991).

Serum superoxide dismutase (SOD) activity was measured by commercial assays (Cayman, Ann Arbor, Michigan).

Plasma levels of monocyte chemoattractant protein-1 (MCP-1), soluble vascular cell adhesion molecule-1 (sVCAM-1), and high-sensitivity C-reactive protein (hsCRP) were determined by enzyme-linked immunosorbent assay (Quantikine; R\&D Systems Inc, Minneapolis, Minn). Normal range og hsCRP is below $1 \mu \mathrm{g} / \mathrm{ml}$. Enzyme-linked immunosorbent assay kits were used to measure plasma level of the endogenous endothelial nitric oxide synthase competitive inhibitor asymmetrical dimethylarginine (ADMA) (Alpco, Salem, NH).

Peripheral blood was drawn by sodium heparin washed syringes. Blood was processed in the flow cytometry unit of the research unit and analyzed on the Coulter Epics XL/MCL.

\section{Detailed gating strategy.}

The analysis was performed with software Kaluza 1.5.20207.16062, Beckman Coulter, Inc.

Blood tubes:

1. Tregs: CD3/CD4/CD25/FoxP3 (CD3, CD4, CD25 from Beckman Coulter, FoxP3 from Biolegend, Fix and Perm from eBiosciences) according to Grant et al protocol.

2. B cell heavy chain expression: CD19/lgG/lgM

3. NK cell subsets: CD45/CD3/CD16/CD56

4. Leukocyte subsets for reference: CD45/CD3/CD19/CD14

When no special protocol is indicated, cells were stained as whole blood for 15 minutes at room temperature in the dark, hemolyzed and read on the flow cytometer (known as lyze and no wash). 
Data were analyzed with the Expo32 software provided by Beckman Coulter and exported to Excel for statistical analysis.

\section{Data analysis:}

For continuous variables, summary tables provided arithmetic mean (M) and standard deviation (SD). The MannWhitney non-parametric tests were applied to measure the differences between the two groups (patients and control) before and after treatment for the continuous variables. The Wilcoxon non-parametric test was applied to measure the differences between times in the control group and in the patient group. Pearson correlation test was applied to measure correlations.

P value of $5 \%$ or less was considered statistically significant. The data were analyzed using the SPSS version 24 (SPSS Inc., Chicago, IL, USA).

\section{Declarations}

\section{Declaration of Conflicting Interests}

The authors declare no conflicts of interest with respect to the research, authorship and/or publication of this article.

\section{Funding}

The authors received no financial support for the research, authorship and/or publication of this article.

\section{References}

1. Annacker, O. et al. CD25+ CD4+ T cells regulate the expansion of peripheral CD4 T cells through the production of IL10. J Immunol, 166, 3008-3018 (2001).

2. Aviram, M. Plasma lipoprotein separation by discontinuous density gradient ultracentrifugation in hyperlipoproteinemic patients. Biochem Med, 30, 111-118 (1983).

3. Aviram, M. et al. Human serum paraoxonase (PON 1) is inactivated by oxidized low density lipoprotein and preserved by antioxidants. Free Radic Biol Med, 26, 892-904 (1999).

4. Basterzi, A. D. et al. Effects of venlafaxine and fluoxetine on lymphocyte subsets in patients with major depressive disorder: a flow cytometric analysis. Prog Neuropsychopharmacol Biol Psychiatry, 34, 70-75 (2010).

5. Bodi, V. et al. Uncontrolled immune response in acute myocardial infarction: unraveling the thread. Am Heart J, 156, 1065-1073 (2008).

6. Broz, P. \& Dixit, V. M. Inflammasomes: mechanism of assembly, regulation and signalling. Nature Rev Immunol, 16, 407-420 (2016).

7. Darko, D. F. et al. Mitogen-stimulated lymphocyte proliferation and pituitary hormones in major depression. Biol Psychiatry, 26, 145-155 (1989).

8. Dawood, T., Barton, D. A., Lambert, E. A., Eikelis, N. \& Lambert, G. W. Examining endothelial function and platelet reactivity in patients with depression before and after SSRI therapy. Front Psychiatry, 7, 18 (2016).

9. Deknuydt, F., Bioley, G., Valmori, D. \& Ayyoub, M. IL-1beta and IL-2 convert human Treg into T(H)17 cells. Clin Immunol, 131, 298-307 (2009).

10. Despres, J. P. \& Lemieux, I. Abdominal obesity and metabolic syndrome., 444, 881-887 (2006).

11. el-Saadani, M. et al. A spectrophotometric assay for lipid peroxides in serum lipoproteins using a commercially available reagent. J Lipid Res, 30, 627-630 (1989). 
12. Esterbauer, H., Striegl, G., Puhl, H. \& Rotheneder, M. Continuous monitoring of in vitro oxidation of human low density lipoprotein. Free Radic Res Commun, 6, 67-75 (1989).

13. Eyre, H. A., Lavretsky, H., Kartika, J., Qassim, A. \& Baune, B. T. Modulatory effects of antidepressant classes on the innate and adaptive immune system in Ddpression., 49, 85-96 (2016).

14. Farid Hosseini, R. et al. Assessment of the immune system activity in Iranian patients with Major Depression Disorder (MDD). Iran J Immunol, 4, 38-43 (2007).

15. Fazzino, F. et al. Taurine transporter in lymphocytes of patients with major depression treated with venlafaxine plus psychotherapy. Adv Exp Med Biol, 643, 217-224 (2009).

16. Furlong, C. E., Richter, R. J., Seidel, S. L., Costa, L. G. \& Motulsky, A. G. Spectrophotometric assays for the enzymatic hydrolysis of the active metabolites of chlorpyrifos and parathion by plasma paraoxonase/arylesterase. Anal Biochem, 180, 242-247 (1989).

17. Galecki, P., Szemraj, J., Bienkiewicz, M., Florkowski, A. \& Galecka, E. Lipid peroxidation and antioxidant protection in patients during acute depressive episodes and in remission after fluoxetine treatment. Pharmacol Rep, 61, 436-447 (2009).

18. Gami, A. S. et al. Metabolic syndrome and risk of incident cardiovascular events and death: a systematic review and meta-analysis of longitudinal studies. J Am Coll Cardiol, 49, 403-414 (2007).

19. Gan, K. N., Smolen, A., Eckerson, H. W. \& La Du, B. N. Purification of human serum paraoxonase/arylesterase. Evidence for one esterase catalyzing both activities. Drug Metab Dispos, 19, 100-106 (1991).

20. George, J. et al. Regulatory T cells and IL-10 levels are reduced in patients with vulnerable coronary plaques. Atherosclerosis, 222, 519-523 (2012).

21. Grundy, S. M. Metabolic syndrome: a multiplex cardiovascular risk factor. J Clin Endocrinol Metab, 92, 399-404 (2007).

22. Grundy, S. M. et al. Diagnosis and management of the metabolic syndrome: an American Heart Association/National Heart, Lung, and Blood Institute Scientific Statement., 112, 2735-2752 (2005).

23. Haapakoski, R., Mathieu, J., Ebmeier, K. P., Alenius, H. \& Kivimaki, M. Cumulative meta-analysis of interleukins 6 and 1 beta, tumour necrosis factor alpha and C-reactive protein in patients with major depressive disorder. Brain Behav Immun, 49, 206-215 (2015).

24. Hansson, G. K. \& Libby, P. The immune response in atherosclerosis: a double-edged sword. Nat Rev Immunol, 6, 508-19 (2006).

25. Herken, H. et al. Adenosine deaminase, nitric oxide, superoxide dismutase, and xanthine oxidase in patients with major depression: impact of antidepressant treatment. Arch Med Res, 38, 247-252 (2007).

26. Himmerich, H. et al. Regulatory T cells increased while IL-1beta decreased during antidepressant therapy. $J$ Psychiatr Res, 44, 1052-1057 (2010).

27. Ivanova, S. A. et al. Signs of apoptosis of immunocompetent cells in patients with depression. Neurosci Behav Physiol, 37, 527-530 (2007).

28. Karlsson, H., Gu, Y., DePierre, J. \& Nassberger, L. Induction of apoptosis in proliferating lymphocytes by tricyclic antidepressants., 3, 255-260 (1998).

29. Kin, N. W. \& Sanders, V. M. It takes nerve to tell T and B cells what to do. J Leukoc Biol, 79, 1093-1104 (2006).

30. Kopf, D. et al. Lipid metabolism and insulin resistance in depressed patients: significance of weight, hypercortisolism, and antidepressant treatment. J Clin Psychopharmacol, 24, 527-531 (2004).

31. Kotan, V. O., Sarandol, E., Kirhan, E., Ozkaya, G. \& Kirli, S. Effects of long-term antidepressant treatment on oxidative status in major depressive disorder: a 24-week follow-up study. Prog Neuropsychopharmacol Biol Psychiatry, 35, 1284-1290 (2011).

Page $12 / 22$ 
32. Lehto, S. M. et al. Serum chemokine levels in major depressive disorder., 35, 226-232 (2010a).

33. Lehto, S. M. et al. Low serum HDL-cholesterol levels are associated with long symptom duration in patients with major depressive disorder. Psychiatry Clin Neurosci, 64, 279-283 (2010b).

34. Levy, E. M. et al. Biological measures and cellular immunological function in depressed psychiatric inpatients. Psychiatry Res, 36, 157-167 (1991).

35. Li, Y. et al. Altered expression of $\mathrm{CD} 4(+) \mathrm{CD} 25(+)$ regulatory $\mathrm{T}$ cells and its 5-HT(1a) receptor in patients with major depression disorder. $J$ Affect Disord, 124, 68-75 (2010).

36. Lopresti, A. L. Cognitive behaviour therapy and inflammation: A systematic review of its relationship and the potential implications for the treatment of depression. Aust N Z J Psychiatry, 51, 565-582 (2017).

37. Lowry, O. H., Rosebrough, N. J., Farr, A. L. \& Randall, R. J. Protein measurement with the Folin phenol reagent. J Biol Chem, 193, 265-275 (1951).

38. Lustman, P. J., Freedland, K. E., Griffith, L. S. \& Clouse, R. E. Fluoxetine for depression in diabetes: a randomized double-blind placebo-controlled trial., 23, 618-623 (2000).

39. Marazziti, D. et al. Immune cell imbalance in major depressive and panic disorders., 26, 23-26 (1992).

40. Miller, A. H. Depression and immunity: a role for T cells? Brain Behav Immun, 24, 1-8 (2010).

41. Miller, A. H. \& Raison, C. L. The role of inflammation in depression: from evolutionary imperative to modern treatment target. Nature Rev Immunol, 16, 22-34 (2016).

42. Muller, N., Hofschuster, E., Ackenheil, M., Mempel, W. \& Eckstein, R. Investigations of the cellular immunity during depression and the free interval: evidence for an immune activation in affective psychosis. Prog Neuropsychopharmacol Biol Psychiatry, 17, 713-730 (1993).

43. Paslakis, G. et al. The effect of a 4-week treatment with reboxetine on metabolic parameters of depressed inpatients. Eur Arch Psychiatry Clin Neurosci, 261, 173-177 (2011).

44. Pavon, L. et al. Th2 cytokine response in Major Depressive Disorder patients before treatment. J Neuroimmunol, 172, 156-165 (2006).

45. Piletz, J. E. et al. Pro-inflammatory biomakers in depression: treatment with venlafaxine. World J Biol Psychiatry, 10, 313-323 (2009).

46. Poli, A. et al. CD56bright natural killer (NK) cells: an important NK cell subset., 126, 458-465 (2009).

47. Ravindran, A. V., Griffiths, J., Merali, Z. \& Anisman, H. Circulating lymphocyte subsets in major depression and dysthymia with typical or atypical features. Psychosom Med, 60, 283-289 (1998).

48. Robertson, A. K. et al. Disruption of TGF-beta signaling in T cells accelerates atherosclerosis. J Clin Invest, 112, 1342-1350 (2003).

49. Sadeghi, M. et al. Relationship between depression and apolipoproteins A and B: a case-control study. Clinics (Sao Paulo), 66, 113-117 (2011).

50. Sarandol, A. et al. Major depressive disorder is accompanied with oxidative stress: short-term antidepressant treatment does not alter oxidative-antioxidative systems. Hum Psychopharmacol, 22, 67-73 (2007).

51. Sarandol, A. et al. Oxidation of apolipoprotein B-containing lipoproteins and serum paraoxonase/arylesterase activities in major depressive disorder. Prog Neuropsychopharmacol Biol Psychiatry, 30, 1103-1108 (2006).

52. Selley, M. L. Increased (E)-4-hydroxy-2-nonenal and asymmetric dimethylarginine concentrations and decreased nitric oxide concentrations in the plasma of patients with major depression. J Affect Disord, 80, 249-256 (2004).

53. Sommershof, A. et al. Substantial reduction of naive and regulatory T cells following traumatic stress. Brain Behav Immun, 23, 1117-1124 (2009). 
54. Stefanescu, C. \& Ciobica, A. The relevance of oxidative stress status in first episode and recurrent depression. $J$ Affect Disord, 143, 34-38 (2012).

55. Surtees, P. G. et al. No association between APOE and major depressive disorder in a community sample of 17,507 adults. J Psychiatr Res, 43, 843-847 (2009).

56. Sutcigil, L. et al. (2007) Pro- and anti-inflammatory cytokine balance in major depression: effect of sertraline therapy. Clin Dev Immunol 2007:76396

57. Szuster-Ciesielska, A. et al. Accelerated apoptosis of blood leukocytes and oxidative stress in blood of patients with major depression. Prog Neuropsychopharmacol Biol Psychiatry, 32, 686-694 (2008).

58. Tiemessen, M. M. et al. CD4+CD25+Foxp3+ regulatory T cells induce alternative activation of human monocytes/macrophages. Proc Natl Acad Sci USA, 104, 19446-19451 (2007).

59. Toben, C. \& Baune, B. T. An act of balance between adaptive and maladaptive immunity in depression: a role for T lymphocytes. J Neuroimmune Pharmacol, 10, 595-609 (2015).

60. Vaccarino, V. et al. Association of major depressive disorder with serum myeloperoxidase and other markers of inflammation: a twin study. Biol Psychiatry, 64, 476-483 (2008).

61. van Reedt Dortland, A. K. et al. Associations between serum lipids and major depressive disorder: results from the Netherlands Study of Depression and Anxiety (NESDA). J Clin Psychiatry, 71, 729-736 (2010).

62. Williams, L. M. \& Rudensky, A. Y. Maintenance of the Foxp3-dependent developmental program in mature regulatory T cells requires continued expression of Foxp3. Nature Immunol, 8, 277-284 (2007).

63. Ying, G., Karlsson, H., DePierre, J. W. \& Nassberger, L. Tricyclic antidepressants prevent the differentiation of monocytes into macrophage-like cells in vitro. Cell Biol Toxicol, 18, 425-437 (2002).

\section{Tables}

Table 1: Laboratory parameters (Mean \pm SD) 
Page 15/22 
Control

Before

Glucose

Uric acid

Total Cholesterol

Triglycerides

HDL-C

LDL-C

VLDL-C

ALT

AST

Alkaline phosphatase

GGT

Weight (kg)

BMI $\left(\mathrm{kg} / \mathrm{h}^{2}\right)$

Systolic pressure

Diastolic

pressure

Pulse \minute

waist

circumference

(cm)

HOMA-IR
HOMA-beta (\%)
8-iso-PGF
(ng/ml)
Basal MDA
(nmol/ml)
Ox.MDA
(nmol/ml)
$\begin{aligned} & \text { Delta MDA } \\ & \text { (nmol/ml) }\end{aligned}$
PD's (nmol/ug
protein)
CD (O.D/ug
protein)
Hamilton
depression rating
scale

Depression

After $\mathrm{p}^{\star}$ Before After $\mathrm{p}^{\star \star} \quad \mathrm{p}^{\#} \quad \mathrm{P}^{\# \#}$

$\begin{array}{llllllll}88.2 \pm 9.5 & 87.7 \pm 14.0 & 0.859 & 89.8 \pm 14.1 & 85.3 \pm 12.3 & 0.093 & 0.998 & 0.935\end{array}$

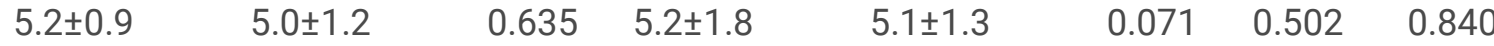

$\begin{array}{llllllll}203.0 \pm 42.3 & 187.0 \pm 27.9 & 0.515 & 197.7 \pm 41.3 & 204.0 \pm 56.5 & 0.399 & 0.936 & 0.374\end{array}$

$\begin{array}{llllllll}95.8 \pm 32.6 & 83.6 \pm 26.7 & 0.285 & 134.8 \pm 59.8 & 164.5 \pm 78.3 & 0.008 & 0.034 & 0.001\end{array}$

$\begin{array}{llllllll}52.3 \pm 9.3 & 55.7 \pm 18.3 & 0.767 & 46.2 \pm 10.9 & 48.2 \pm 10.3 & 0.351 & 0.072 & 0.338\end{array}$

$\begin{array}{llllllll}131.5 \pm 38.6 & 114.6 \pm 22.0 & 0.214 & 124.1 \pm 35.3 & 124.0 \pm 46.6 & 0.903 & 0.646 & 0.486\end{array}$

$\begin{array}{llllllll}19.3 \pm 6.7 & 16.6 \pm 5.4 & 0.228 & 30.5 \pm 21.3 & 32.8 \pm 15.6 & 0.070 & 0.030 & 0.001\end{array}$

$\begin{array}{llllllll}19.3 \pm 8.3 & 18.6 \pm 8.6 & 0.677 & 21.5 \pm 14.8 & 35.1 \pm 36.0 & 0.040 & 0.974 & 0.249\end{array}$

$\begin{array}{llllllll}20.3 \pm 4.0 & 20.4 \pm 5.5 & 0.526 & 21.2 \pm 7.0 & 29.4 \pm 15.5 & 0.026 & 0.872 & 0.169\end{array}$

$\begin{array}{llllllll}59.6 \pm 11.1 & 66.3 \pm 16.1 & 0.021 & 76.3 \pm 17.8 & 87.6 \pm 25.2 & 0.076 & 0.005 & 0.025\end{array}$

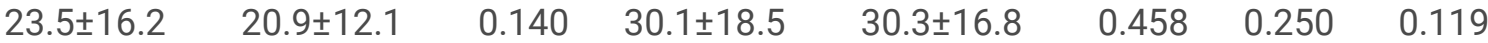

$\begin{array}{llllllll}70.1 \pm 18.0 & 69.6 \pm 18.5 & 0.024 & 75.5 \pm 13.8 & 74.4 \pm 12.8 & 0.681 & 0.253 & 0.249\end{array}$

$\begin{array}{llllllll}25.4 \pm 4.4 & 25.6 \pm 4.2 & 0.080 & 26.9 \pm 5.4 & 27.1 \pm 5.2 & 0.397 & 0.520 & 0.449\end{array}$

$\begin{array}{llllllll}116.0 \pm 13.3 & 113.9 \pm 14.4 & 0.231 & 124.2 \pm 16.4 & 122.6 \pm 20.0 & 0.475 & 0.152 & 0.211\end{array}$ $\begin{array}{llllllll}76.5 \pm 8.4 & 71.6 \pm 10.6 & 0.021 & 80.4 \pm 9.4 & 80.5 \pm 9.7 & 0.998 & .0 .259 & 0.015\end{array}$

$\begin{array}{llllllll}71.0 \pm 6.4 & 77.9 \pm 12.8 & 0.260 & 81.4 \pm 14.2 & 79.7 \pm 13.3 & 0.375 & 0.017 & 0.740\end{array}$

$\begin{array}{llllllll}90.7 \pm 9.8 & 88.6 \pm 11.0 & 0.854 & 92.9 \pm 12.1 & 96.5 \pm 26.6 & 0.968 & 0.690 & 0.587\end{array}$

$\begin{array}{llllllll}1.4 \pm 0.7 & 1.0 \pm 0.6 & 0.779 & 1.7 \pm 1.7 & 1.6 \pm 1.9 & 0.179 & 0.969 & 0.794\end{array}$

$\begin{array}{llllllll}102.2 \pm 60.4 & 111.6 \pm 95.2 & 0.674 & 102.6 \pm 53.2 & 127.8 \pm 97.6 & 0.478 & 0.969 & 0.542\end{array}$

$\begin{array}{llllllll}3.2 \pm 3.3 & 3.8 \pm 2.6 & 0.779 & 4.4 \pm 5.3 & 3.5 \pm 4.2 & 0.162 & 0.723 & 0.401\end{array}$

$\begin{array}{llllllll}1.7 \pm 0.5 & 1.6 \pm 0.7 & 0.008 & 2.2 \pm 1.8 & 2.2 \pm 1.5 & 0.000 & 0.949 & 0.682\end{array}$

$\begin{array}{llllllll}7.4 \pm 1.0 & 7.4 \pm 1.8 & 0.859 & 7.7 \pm 2.3 & 8.7 \pm 2.8 & 0.054 & 0.403 & 0.166\end{array}$

$\begin{array}{llllllll}5.7 \pm 1.1 & 5.7 \pm 1.6 & 0.594 & 5.5 \pm 2.3 & 6.6 \pm 2.5 & 0.162 & 0.847 & 0.301\end{array}$

$\begin{array}{llllllll}0.6 \pm 0.2 & 0.5 \pm 0.2 & 0.678 & 1.0 \pm 0.5 & 1.3 \pm 0.7 & 0.135 & 0.001 & 0.000\end{array}$

$\begin{array}{llllllll}4.9 \pm 0.7 & 5.1 \pm 0.6 & 0.066 & 5.2 \pm 2.6 & 6.2 \pm 3.2 & 0.264 & 0.723 & 0.626\end{array}$

$27.1 \pm 7.7 \quad 10.8 \pm 5.7 \quad 0.000$ 
$P$ value for difference between: * Control group at visit 1 vs visit 2, ** Depressive group at visit 1 vs visit 2, \# Control group vs depressive group at visit1, \#\# Control group vs depressive group at visit 2

Table 2

Flow cytometry of MDD patients' leukocytes (Mean \pm SD)

\begin{tabular}{|c|c|c|c|c|c|c|c|c|}
\hline & Control & & & Depression & & & & \\
\hline & Before & After & $p^{*}$ & Before & After & $p^{* \star}$ & $\mathrm{p}^{\#}$ & $\mathrm{P}^{\# \#}$ \\
\hline $\begin{array}{l}\text { Percent } \\
\text { CD19 } \\
\text { lymphocytes }\end{array}$ & $8.53 \pm 3.02$ & $9.64 \pm 2.40$ & 0.260 & $9.12 \pm 3.13$ & $9.67 \pm 5.15$ & 0.346 & 0.703 & 0.571 \\
\hline $\begin{array}{l}\text { Percent } \\
\text { gated IgG } \\
\text { CD19 }\end{array}$ & $2.79 \pm 2.10$ & $3.40 \pm 2.20$ & 0.260 & $4.74 \pm 3.81$ & $5.15 \pm 4.60$ & 0.563 & 0.063 & 0.442 \\
\hline $\begin{array}{l}\lg G \lg M \\
\text { ratio }\end{array}$ & $0.06 \pm 0.04$ & $0.62 \pm 0.04$ & 0.678 & $0.08 \pm 0.08$ & $0.10 \pm 0.12$ & 0.429 & 0.426 & 0.746 \\
\hline $\begin{array}{l}\text { Percent } \\
\text { gated CD } 56 \\
\text { lymphocytes }\end{array}$ & $17.40 \pm 3.75$ & $17.93 \pm 5.68$ & 0.515 & $19.86 \pm 7.29$ & $20.11 \pm 6.91$ & 0.546 & 0.241 & 0.352 \\
\hline $\begin{array}{l}\text { Percent NK } \\
\text { FS SSC } \\
\text { lymphocytes }\end{array}$ & $83.71 \pm 18.47$ & $84.25 \pm 10.1$ & 0.594 & $82.99 \pm 14.25$ & $81.86 \pm 15.67$ & 0.101 & 0.466 & 0.352 \\
\hline $\begin{array}{l}\text { CD56 MFI } \\
\text { NK FS SSC }\end{array}$ & $5.65 \pm 0.95$ & $6.65 \pm 3.29$ & 0.441 & $6.88 \pm 2.16$ & $6.38 \pm 3.15$ & 0.149 & 0.174 & 0.777 \\
\hline $\begin{array}{l}\text { CD16 MFI } \\
\text { NK FS SSC }\end{array}$ & $13.66 \pm 7$ & $16.88 \pm 6.74$ & 0.515 & $17.38 \pm 8.60$ & $15.06 \pm 8.17$ & 0.212 & 0.398 & 0.746 \\
\hline
\end{tabular}

\section{Figures}




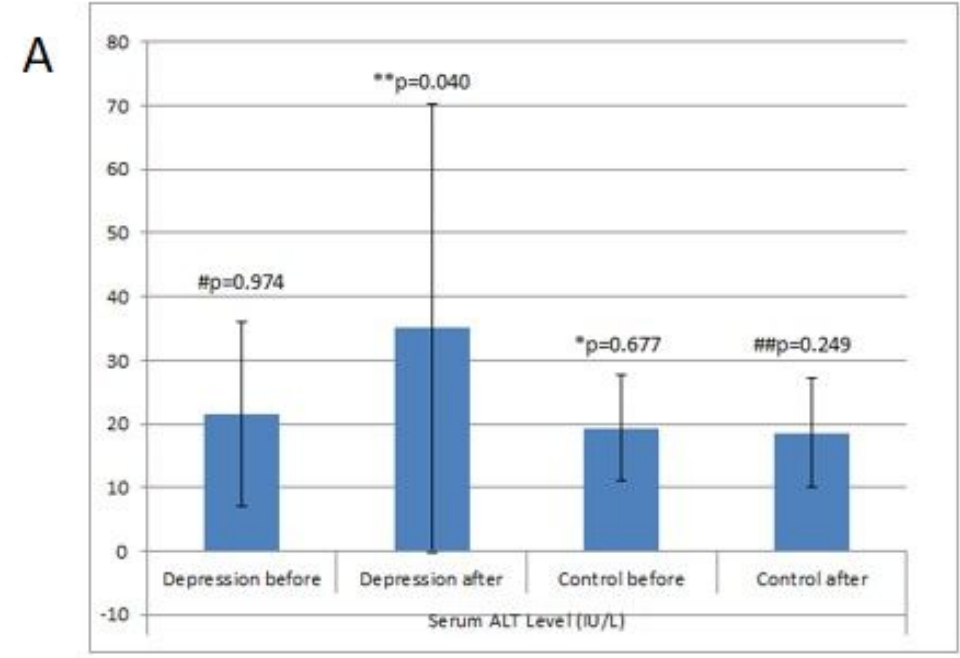

B
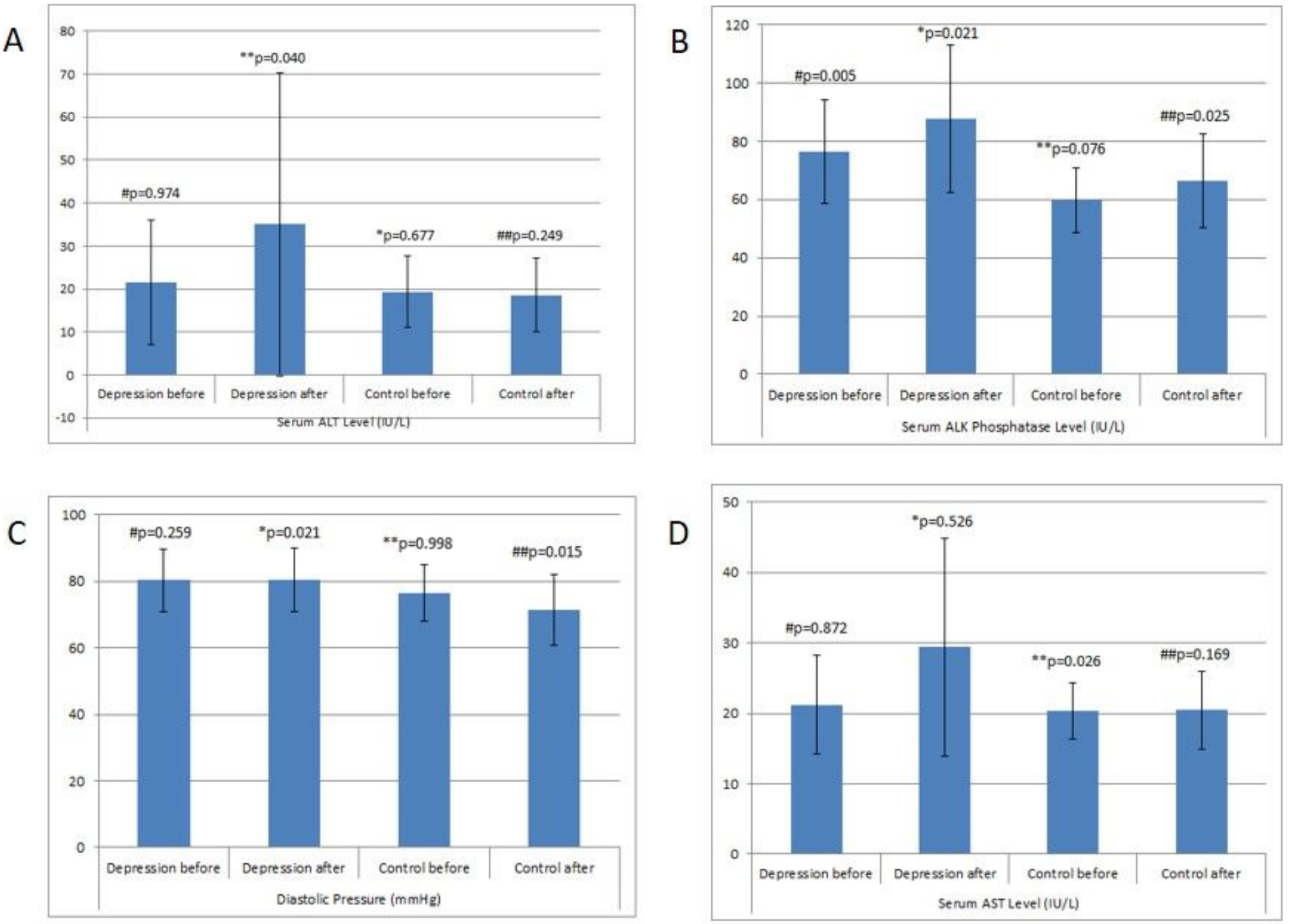

Figure 1

\section{Figure 1}

Serum liver function tests and diastolic blood pressure V1 Baseline visit, V2 Visit 2 for patients after 8 weeks of pharmacologic treatment or for controls, * Significant difference between controls at V1 and V2, ** Significant difference between patients at V1 and V2, \# Significant difference between patients and controls at V1, \#\# significant difference between patients and controls at visit 2 ALT: alanine transferase 
A

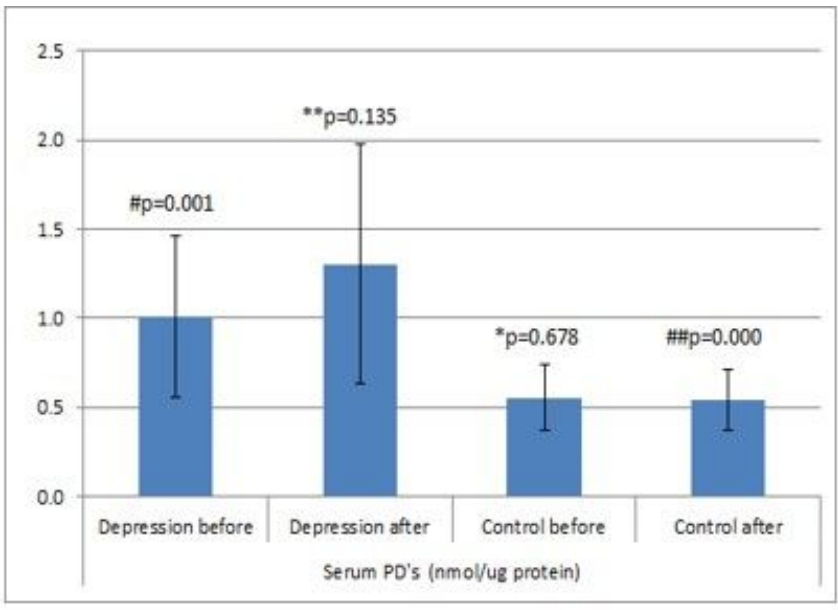

$\mathrm{C}$

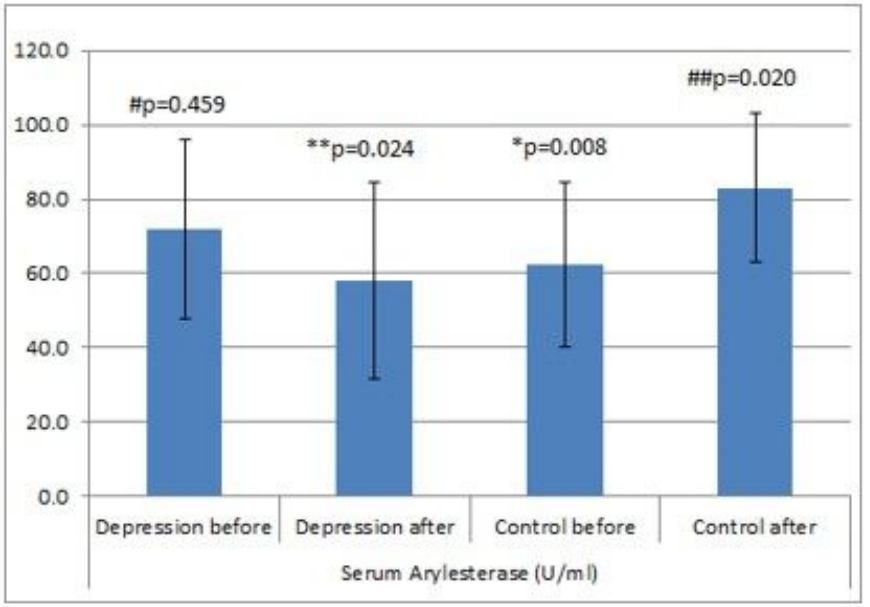

B

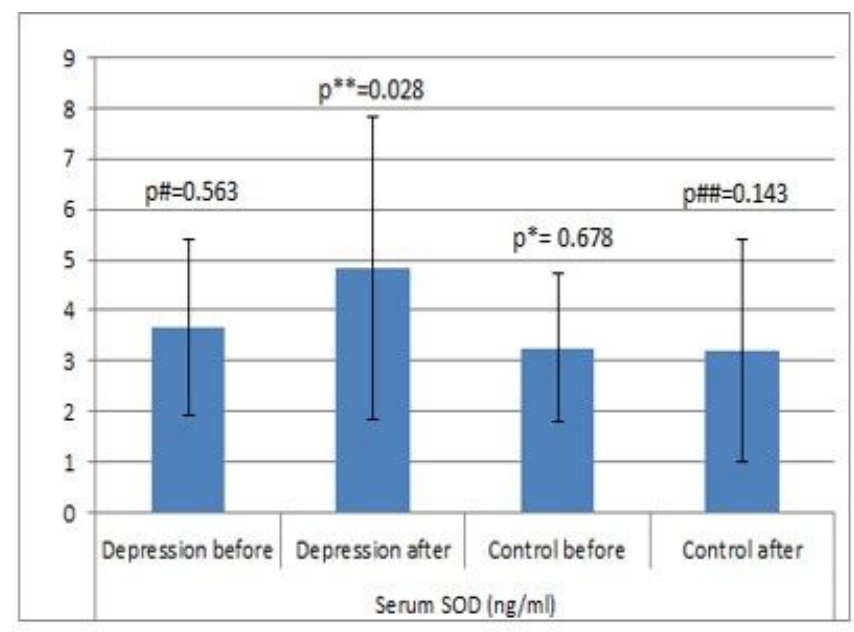

D

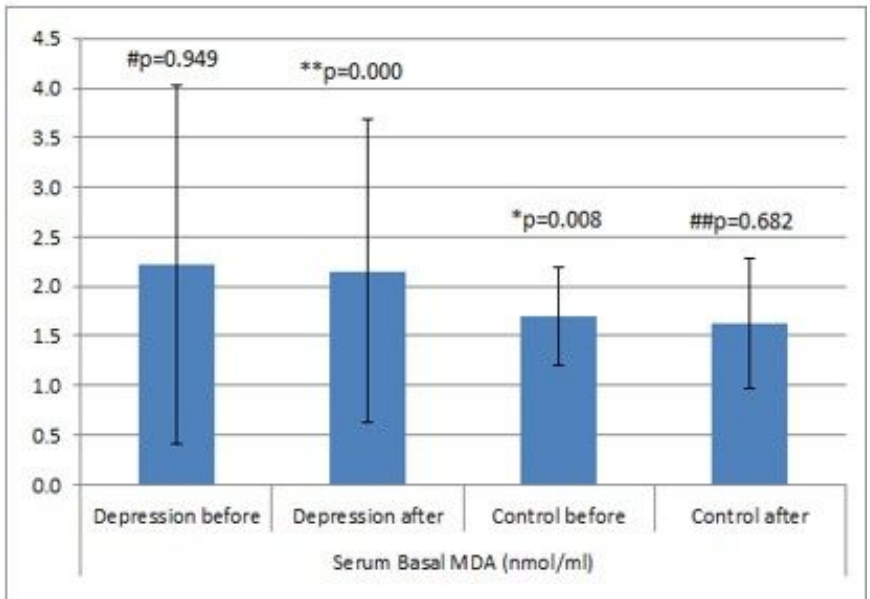

Figure 2

\section{Figure 2}

Oxidative stress tests in the serum V1 Baseline visit, V2 Visit 2 for patients after 8 weeks of pharmacologic treatment or for controls, * Significant difference between controls at V1 and V2, ** Significant difference between patients at V1 and V2, \# Significant difference between patients and controls at V1, \#\# significant difference between patients and controls at visit 2 PD: peroxide, SOD: superoxide dismutase, MDA: malonyl dialdehyde 
A

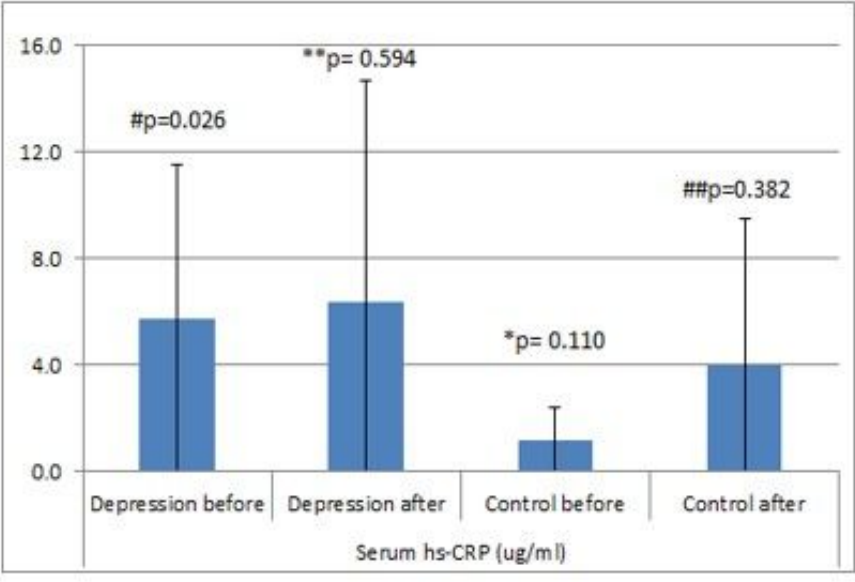

B

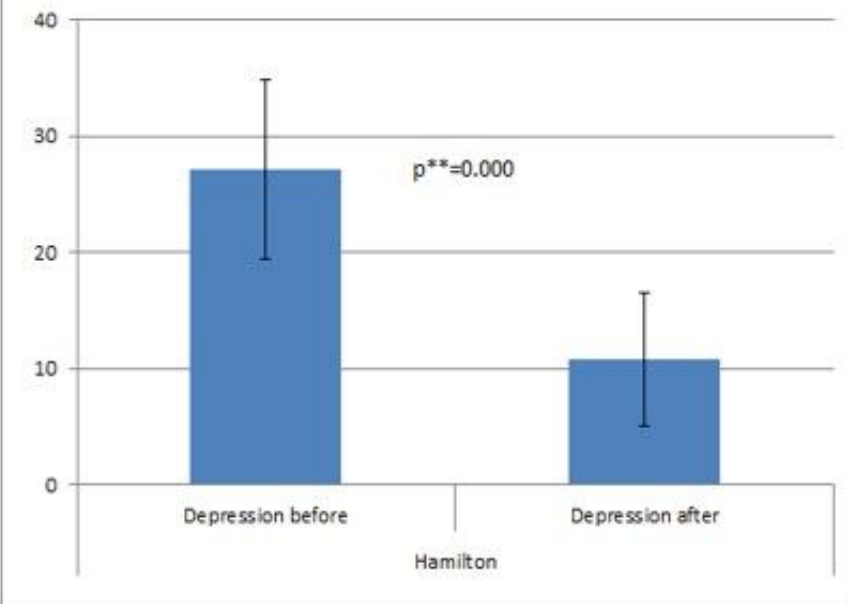

$\mathrm{C}$

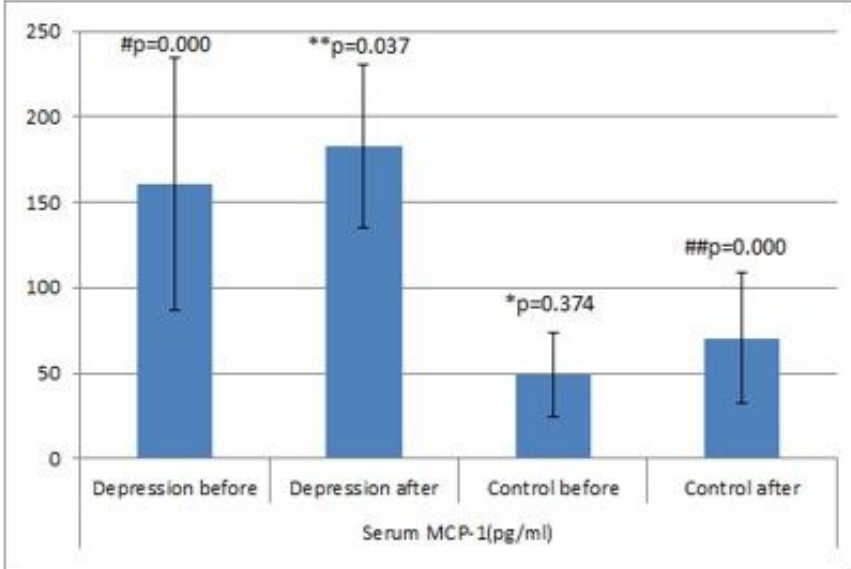

D

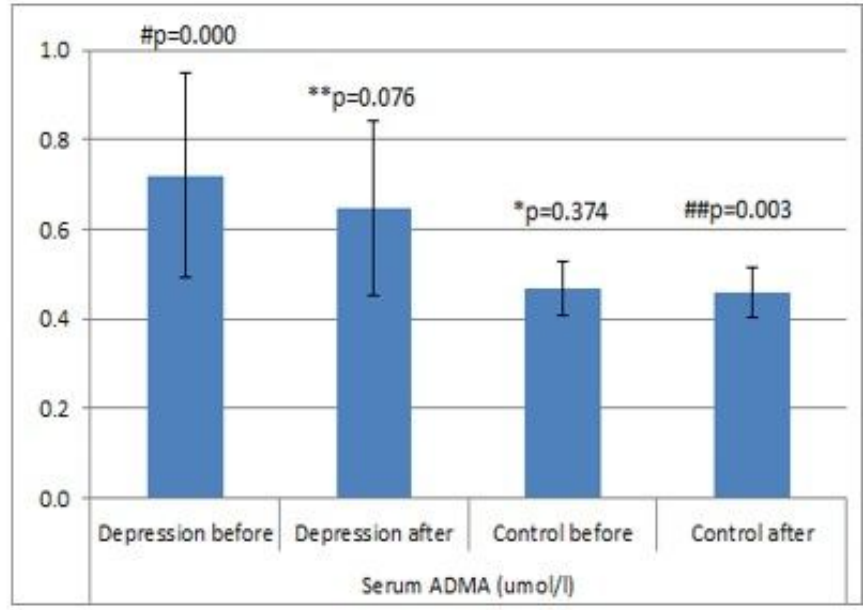

Figure 3

\section{Figure 3}

Serum inflammatory parameters and ADMA and Hamilton test results V1 Baseline visit, V2 Visit 2 for patients after 8 weeks of pharmacologic treatment or for controls, * Significant difference between controls at V1 and V2, ** Significant difference between patients at V1 and V2, \# Significant difference between patients and controls at V1, \#\# significant difference between patients and controls at visit 2 hs-CRP: high-sensitivity C-reactive protein, MCP-1: monocyte chemoattractant protein-1, ADMA: asymmetrical dimethylarginine, Hamilton: Hamilton Depression Rating Scale 
A

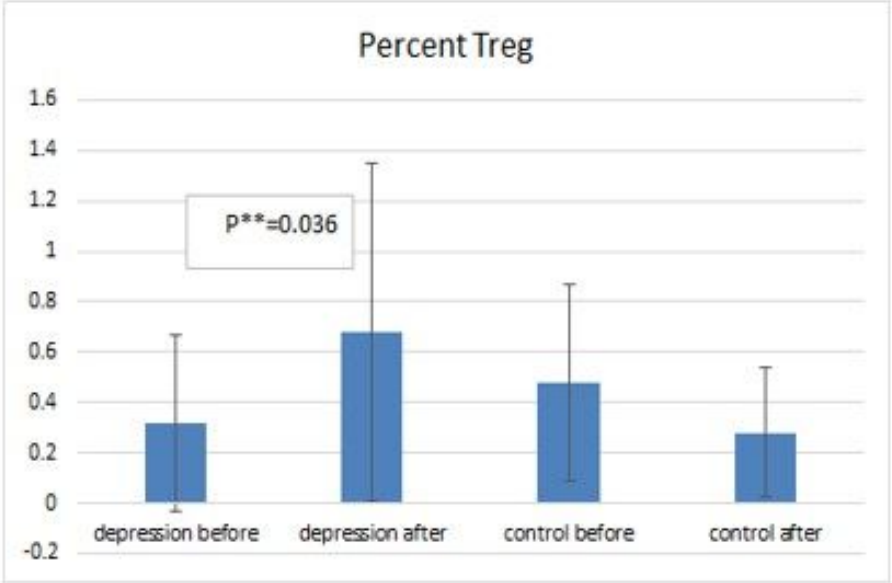

B

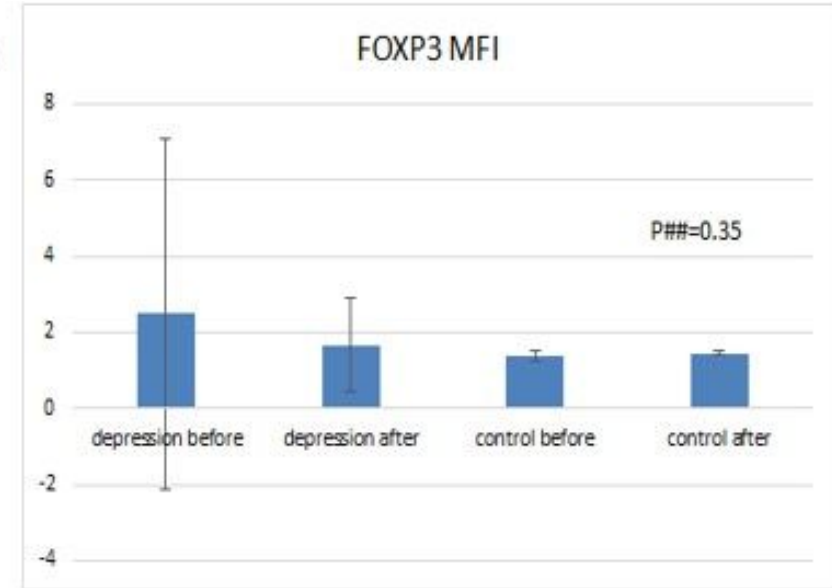

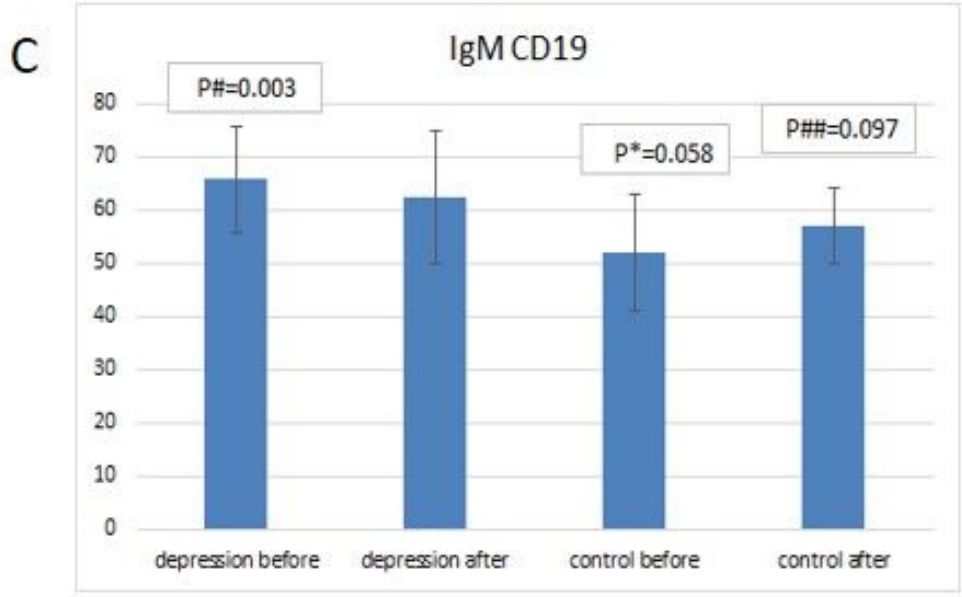

\section{Figure 4}

\section{Figure 4}

Flow cytometry of MDD patients' leukocytes V1 Baseline visit, V2 Visit 2 for patients after 8 weeks of pharmacologic treatment or for controls, * Significant difference between controls at V1 and V2, ** Significant difference between patients at V1 and V2, \# Significant difference between patients and controls at V1, \#\# significant difference between patients and controls at visit 2 Treg: Regulatory T cell, MFI: mean fluorescent intensity 
A

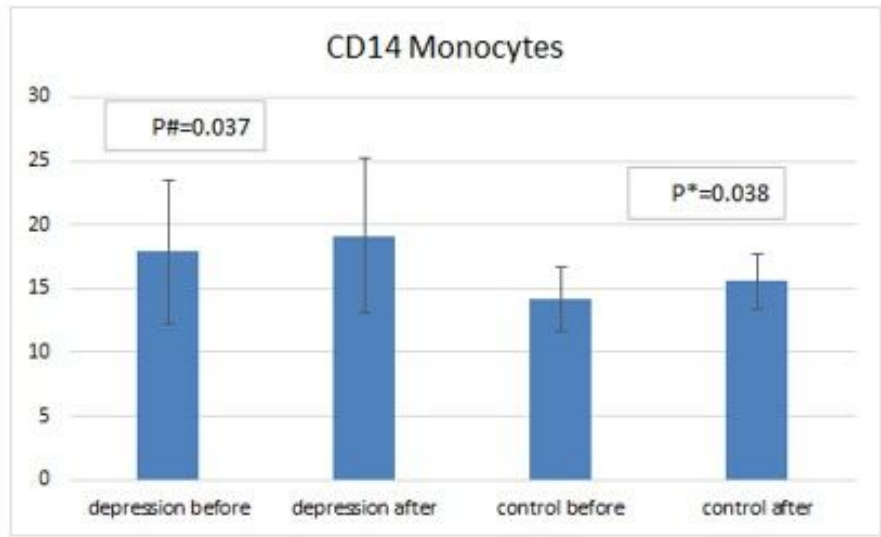

B

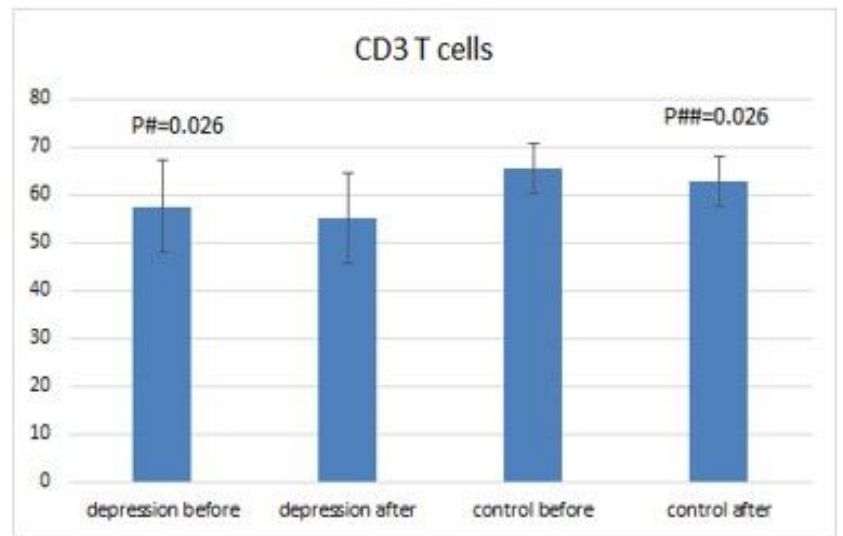

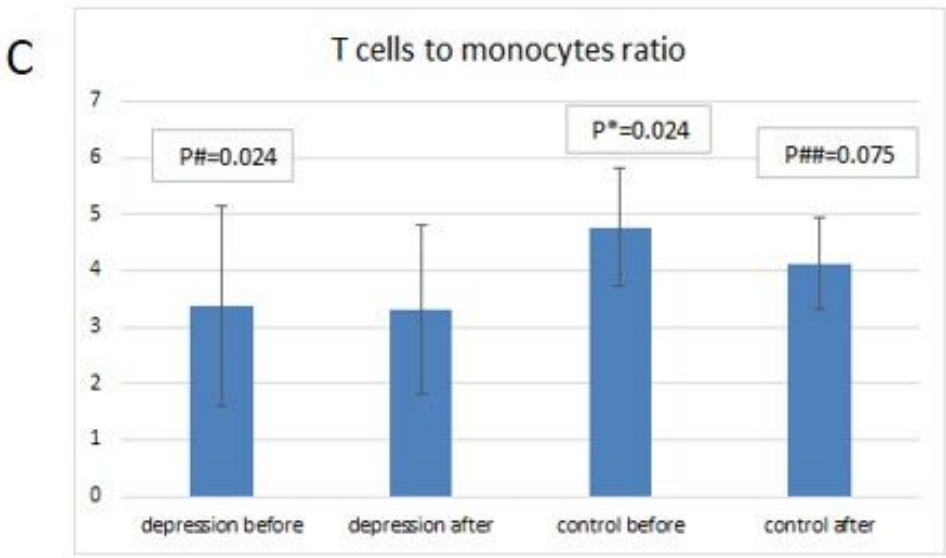

\section{Figure 5}

\section{Figure 5}

Flow cytometry of MDD patients' leukocytes V1 Baseline visit, V2 Visit 2 for patients after 8 weeks of pharmacologic treatment or for controls, * Significant difference between controls at V1 and V2, ** Significant difference between patients at V1 and V2, \# Significant difference between patients and controls at V1, \#\# significant difference between patients and controls at visit 2. 